\title{
Enhancing the Knowledge of Cervical Cancer Screening among Female Nursing Students: An Interventional Educational Program
}

\section{Dr: Hayam Fathey A. Eittah, Dr: Khalid Abdullah S. Aljohani, and Dr: Mohammed Saeed E. Aljohani}

${ }^{1}$ Assist. Prof. of Maternal and Newborn Health Nursing, Faculty of Nursing, Menoufia University, Egypt

Associate Prof. of Maternal and Newborn Health Nursing, Nursing College, Taibah University Madinah, KSA

${ }^{2}$ Assist. Professor, Community Health Nursing, Nursing College, Taibah University, Madinah, KSA

${ }^{3}$ Assistant Professor, Medical and Surgical Nursing, Nursing College, Taibah University, Madinah, KSA

Corresponding Author:

Khalid Abdullah S. Aljohani;

Assist. Professor, Community

Health Nursing, Nursing

College, Taibah University,

Madinah, KSA

email:

kajohani@taibahu.edu.sa

Received 9 October 2020

Accepted 19 December 2020

Published 31 December 2020

Production and Hosting by

Knowledge E

(c) Hayam Fathey A. Eittah

et al. This article is distributed under the terms of the

Creative Commons

Attribution License, which

permits unrestricted use and redistribution provided that the original author and source are credited.

Editor-in-Chief:

Prof. Mohammad A. M. Ibnouf

\section{Abstract}

Background: Cervical cancer is a growing health risk facing women worldwide with the human papillomavirus (HPV) as the primary underlying cause. Pap smear is a simple screening test that can detect early changes in cervical cells, which might develop into cancer cells. Raising awareness of cervical cancer prevention has a significant impact on decreasing the burden of the disease. The aim of the study is to assess female nursing students' knowledge on early detection and screening of cervical cancer, and to determine the effectiveness of an educational program.

Methods: A quasi-experimental research design (one group for pre- and post-tests) was utilized with a convenience sample of 130 female nursing students in one of the nursing colleges in Saudi Arabia. The study's educational intervention included information about anatomy of genital tract and the importance of regular check-ups. The pre- and post-tests were applied to identify changes after intervention measures. Results: The mean age of the participants were 21.32 years (SD: 1.34). The findings revealed a significant improvement of post-test students' knowledge in all items related to risk factors, signs and symptoms, occurrence, identification of HPV as causative agent, vaccination against HPV, and finally Pap smear for early detection and screening of cervical cancer.

Conclusion: The study results support implementing educational intervention to improve nursing students' knowledge and awareness about cervical cancer prevention. Furthermore, it is imperative that cervical cancer awareness education modules should be developed and integrated within the nursing curriculum. Further studies with large sample size are recommended to increase generalization of the results.

Keywords: cervical cancer, education program, primary prevention, nursing students, Saudi Arabia

\section{S OPEN ACCESS}




\section{Introduction}

Cervical cancer is one of the diseases that could be avoided by encouraging people who are at risk to have a regular screening. Increasing people's awareness about the importance of disease screening may encourage them to be actively engaged in disease prevention initiatives. According to the World Health Organization (WHO), cervical cancer is the fourth most common cancer among women, with an estimated 570,000 new cases representing $6.6 \%$ of all female cancers around the world in 2018. Death from cervical cancer in low- and middle-income countries is about $90 \%$ [1]. Factors increasing death in developing countries include lack of awareness and high vaccine costs [2]

From Saudi Arabian context, cervical cancer is not a major contributor to women's health problems in the country. More than $90 \%$ of cervical cancer cases are related to human papillomavirus (HPV) infection [3]. The pathogenesis can develop through precancerous lesions to invasive cancer over a period of 10-20 years and ultimately lead to death [4]. Cancer of the cervix is preventable and can be easily managed if identified at early stages through Pap smear [5]. Unfortunately, about $90 \%$ of deaths did not have regular Pap smear. A recent report mentioned that about 316 new cases of cervical cancer were diagnosed annually in Saudi Arabia. Cervical cancer is the ninth most common cancer among females aged 15-44 years [6]. Henceforth, studies exploring cervical cancer educational interventions are warranted [7].

Effective health education programs targeting cervical cancer awareness need sophisticated and comprehensive planning and needs assessment of the target groups such as the level of knowledge, beliefs, attitudes, and behavior [8, 9]. Comprehensive health education programs are more likely to promote screening, so it is important for health providers including nursing students to provide information about risk factors, early signs of cervical cancer, and encourage women to screen for cervical cancer on a regular basis $[3,10]$.

Raising awareness of cervical cancer prevention has a significant impact on decreasing the burden of the disease. Specifically, evidence has shown that education interventions to raise awareness improve accessibility to services, increase individuals' efficacy, and inspire future choices, which in turn enhance the efficiency of preventive health services [11]. The aim of this study was to assess and enhance female nursing students' knowledge and early detection and screening of cervical cancer utilizing an education program as an intervention. The study hypothesis assumes that educational programs will raise the knowledge and awareness of nursing students about cervical cancer, screening, and early detection.

\section{Methods}

A quasi-experimental design (pre-test-post-test design) was utilized to explore a convenient sample of 130 female nursing students the Nursing College at Taibah University in Saudi Arabia. The study included students who were 18 years or older. Those who 
were younger than 18 years were excluded. Potential candidates were approached and invited to participate in the study.

\subsection{Instrument}

The study instrument consisted of two sections: the first section consisted of the sociodemographic data including age, education level, age of menarche, family history, smoking, and attending an educational session about cervical cancer; while the second section was the pre-post intervention test. As academics, the researchers constructed this section of simple questions recalling knowledge about the importance of genital tract check-ups, diseases that affect the genital tract, definition of cervical cancer, causes and screening, vaccination, HPV, Pap smear definition, importance of test, and the use, technique, periodicity, and precautions before having a Pap smear. This section tested for content validity by five academic nursing experts. Modifications were made according to the experts' assessment. Although the instrument was administered to the same population for more than one session under similar conditions, a pilot study involving 13 participants were undertaken. The final version of the instrument was attained following the pilot study outcome.

Further, the scoring system was adapted from a previous study [12]. In detail, the scoring system classified participants' answers into three categories (wrong answer $=0$, incomplete answer $=1$, and complete answer $=3$ ). The student with a score below $50 \%$ was considered to have poor knowledge. The overall score was classified as follows: low $=<50 \%$; accepted knowledge level $=50-75 \%$; and good knowledge $=>75 \%$. Data were analyzed using the Statistical Package for Social Sciences software package (SPSS Inc., Chicago, IL, USA) version 20.0. Frequencies, percentages, mean, and median were calculated for the knowledge score. Student $t$-test and Chi-square test were utilized to analyze the results. Statistical significance was identified at $P<0.05$.

\subsection{Procedure}

The aim of the study was explained to the participants followed by assessing the pretest knowledge level (estimated time 10-13 min). The intervention was an educational session delivered for 120 min including the following:

1. Anatomy of genital tract and importance of genital tract screening

2. Cervical cancer definition, risk factors, causes, signs, and symptoms

3. The relation between sexual activity and cervical cancer

4. HPV, its vaccine, screening of cervical cancer, pap smear technique, timing, periodicity, and precautions before Pap smear

The researchers used audio-visual aid such as Microsoft PowerPoint presentation, videos, and pictures for explanations. The final stage of post-test followed the education intervention (estimated time 10-13 min). 


\section{Results}

The mean age of the study participants was 21.32 years $(S D=1.34)$, while the mean age of menarche was 12.93 years $(S D=1.39)$. Other sociodemographic characteristics (Table 1) showed that $90 \%$ of study samples were not married. Neither of the participants smoked nor had a family history of cervical cancer. The majority knew about cervical cancer but did not attend any educational session in this regard. Sources of information about cervical cancer were TV, social media, friends, academic study, and reading newspapers $(16.1 \%, 63.1 \%, 2.3 \%, 2.3 \%$, and $16.2 \%$, respectively).

TABLE 1: Sociodemographic characteristics $(n=130)$.

\begin{tabular}{l|c|c|}
\hline Characteristics & No. & $\%$ \\
\hline Marital status & & \\
\hline Single & 117 & 90.0 \\
\hline Married & 13 & 10.0 \\
\hline Smoking status & & \\
\hline Yes & 0 & 0 \\
\hline No & 130 & 100.0 \\
\hline Cervical cancer family history & & \\
\hline Yes & 0 & 0 \\
\hline No & 130 & 100.0 \\
\hline Attended previous educational activity & & \\
\hline Yes & 01 & 0.80 \\
\hline No & 129 & 99.2 \\
\hline Prior knowledge of cervical cancer & & \\
\hline Yes & 99 & 76.2 \\
\hline No & 31 & 23.8 \\
\hline Preferred source of information & & \\
\hline TV & 21 & 16.1 \\
\hline Social media & 82 & 63.1 \\
\hline Friends & 03 & 02.3 \\
\hline Academic study & 03 & \\
\hline Newspapers & & \\
\hline & & \\
\hline
\end{tabular}

As shown in Table 2, high statistically significant improvements were observed in the results of the post-test knowledge of students in the sample regarding the importance of check-up of genital tract, diseases that affect the cervix, risk factors, signs and symptoms of cervical cancer, and the relationship between sexual activity and cervical cancer when compared with the pre-test results, at $P<0.001$. It is evident that the complete and correct answers were 22.3\%, 27.7\%, 6.9\%,3.1\%, 2.3\%, and 42.3\%, respectively in pre-test, while at the post-test, the percentage of complete and correct responses rose, respectively, to $79.2 \%, 89.2 \%, 88.5 \%, 90.0 \%$, and $96.9 \%$. Regarding the students' knowledge about causative organism of cervical cancer (HPV) and its vaccination, there 
TABLE 2: Comparison of the results of pre-post knowledge tests related to cervical cancer, HPV $(n=130)$.

\begin{tabular}{|c|c|c|c|c|c|c|c|}
\hline \multirow{3}{*}{$\begin{array}{l}\text { Knowledge } \\
\text { statements } \\
\text { The importance of } \\
\text { check-up of genital } \\
\text { tract? }\end{array}$} & \multirow{3}{*}{$\begin{array}{l}\text { Answer } \\
\text { Complete }\end{array}$} & \multicolumn{4}{|c|}{ Group test } & \multirow{3}{*}{$\begin{array}{c}\mathbf{X}^{2} \\
94.8\end{array}$} & \multirow{3}{*}{$\begin{array}{l}\text { P-value } \\
0.001^{* *}\end{array}$} \\
\hline & & \multicolumn{2}{|r|}{ Pre } & \multicolumn{2}{|c|}{ Post } & & \\
\hline & & 29 & $22.3 \%$ & 103 & $79.2 \%$ & & \\
\hline & Incomplete & 83 & $63.8 \%$ & 12 & $9.2 \%$ & & \\
\hline & Wrong & 18 & $13.8 \%$ & 15 & $11.5 \%$ & & \\
\hline \multirow{3}{*}{$\begin{array}{l}\text { Diseases affecting } \\
\text { the cervix }\end{array}$} & Complete & 36 & $27.7 \%$ & 116 & $89.2 \%$ & 101.5 & $0.001^{* *}$ \\
\hline & Incomplete & 56 & $43.1 \%$ & 7 & $5.4 \%$ & & \\
\hline & Wrong & 38 & $29.2 \%$ & 7 & $5.4 \%$ & & \\
\hline \multirow{3}{*}{$\begin{array}{l}\text { Knowledge about } \\
\text { cervical cancer }\end{array}$} & Complete & 9 & 06.9\% & 115 & $88.5 \%$ & 176.9 & $0.001^{* *}$ \\
\hline & Incomplete & 63 & $48.5 \%$ & 14 & $10.8 \%$ & & \\
\hline & Wrong & 58 & $44.6 \%$ & 1 & $0.8 \%$ & & \\
\hline \multirow{3}{*}{$\begin{array}{l}\text { Cervical cancer risk } \\
\text { factors }\end{array}$} & Complete & 04 & $03.1 \%$ & 115 & $88.5 \%$ & 200.1 & 0.000 \\
\hline & Incomplete & 43 & $33.1 \%$ & 15 & $11.5 \%$ & & \\
\hline & Wrong & 83 & $63.8 \%$ & 0 & $0.0 \%$ & & \\
\hline \multirow{3}{*}{$\begin{array}{l}\text { Signs and } \\
\text { symptoms of } \\
\text { cervical cancer }\end{array}$} & Complete & 3 & $2.3 \%$ & 117 & $90.0 \%$ & 210.7 & 0.000 \\
\hline & Incomplete & 34 & $26.2 \%$ & 13 & $10.0 \%$ & & \\
\hline & Wrong & 93 & $71.5 \%$ & 0 & $0.0 \%$ & & \\
\hline \multirow{2}{*}{$\begin{array}{l}\text { Relationship } \\
\text { between sexual } \\
\text { activity and cervical } \\
\text { cancer }\end{array}$} & Yes & 55 & $42.3 \%$ & 126 & $96.9 \%$ & 91.7 & 0.000 \\
\hline & No & 75 & $57.7 \%$ & 4 & $3.1 \%$ & & \\
\hline \multirow{3}{*}{$\begin{array}{l}\text { Knowledge about } \\
\text { HPV }\end{array}$} & Complete & 16 & $12.3 \%$ & 126 & $96.9 \%$ & 188.6 & 0.000 \\
\hline & Incomplete & 11 & $8.5 \%$ & 2 & $1.5 \%$ & & \\
\hline & Wrong & 103 & $79.2 \%$ & 2 & $1.5 \%$ & & \\
\hline \multirow[t]{3}{*}{ HPV vaccine } & Complete & 4 & $3.1 \%$ & 122 & $93.8 \%$ & 218.5 & 0.000 \\
\hline & Incomplete & 26 & $20.0 \%$ & 7 & $5.4 \%$ & & \\
\hline & Wrong & 100 & $76.9 \%$ & 1 & $0.8 \%$ & & \\
\hline
\end{tabular}

was a high statistically significant improvement in post-test results as compared to pretest, the complete and correct answers were $96.9 \%, 93.8 \%$ in post-test compared to $12.3 \%$ and $3.1 \%$ in pre-test at $P$-value $=0.000$.

Table 3 shows the comparison of pre- and post-tests knowledge assessment of female students regarding Pap smear definition, associated pain, timing, periodicity, and prior precautions, and statistically significant improvements were observed in all these items, $P=0.000$. At the pre-test, the majority of the students had incorrect and wrong answers but this result was reversed to complete and correct at post-test. 
TABLE 3: Pre-post knowledge of the students regarding Pap smear (screening of cervical cancer) $(n=130)$.

\begin{tabular}{|c|c|c|c|c|c|c|c|}
\hline \multirow[t]{2}{*}{ Answers } & & \multicolumn{4}{|c|}{ Group } & \multirow{3}{*}{$\begin{array}{c}X^{2} \\
221.5\end{array}$} & \multirow{3}{*}{$\begin{array}{l}\text { P-value } \\
0.000\end{array}$} \\
\hline & & \multicolumn{2}{|c|}{ Pre } & \multicolumn{2}{|c|}{ Post } & & \\
\hline \multirow{2}{*}{$\begin{array}{l}\text { Do you know what a } \\
\text { Papanicolaou/Pap smear } \\
\text { is? }\end{array}$} & Yes & 5 & $3.8 \%$ & 125 & $96.2 \%$ & & \\
\hline & No & 125 & $96.2 \%$ & 5 & $3.8 \%$ & & \\
\hline \multirow{3}{*}{$\begin{array}{l}\text { Knowledge about Pap } \\
\text { smear }\end{array}$} & Complete & 7 & $5.4 \%$ & 110 & $84.6 \%$ & 181.1 & 0.000 \\
\hline & Incomplete & 19 & $14.6 \%$ & 15 & $11.5 \%$ & & \\
\hline & Wrong & 104 & $80.0 \%$ & 5 & $3.8 \%$ & & \\
\hline \multirow{2}{*}{$\begin{array}{l}\text { Is there pain during Pap } \\
\text { smear? }\end{array}$} & Yes & 94 & $72.3 \%$ & 119 & $91.5 \%$ & 23.8 & 0.000 \\
\hline & No & 36 & $27.7 \%$ & 11 & $8.5 \%$ & & \\
\hline \multirow{3}{*}{$\begin{array}{l}\text { Recommended age and } \\
\text { frequency for performing } \\
\text { of Pap smear }\end{array}$} & Complete & 3 & $2.3 \%$ & 123 & $94.6 \%$ & 222.7 & 0.000 \\
\hline & Incomplete & 27 & $20.8 \%$ & 4 & $3.1 \%$ & & \\
\hline & Wrong & 100 & $76.9 \%$ & 3 & $2.3 \%$ & & \\
\hline \multirow{3}{*}{$\begin{array}{l}\text { Precautions before } \\
\text { performing Pap smear }\end{array}$} & Complete & 2 & $1.5 \%$ & 117 & $90.0 \%$ & 222.1 & 0.000 \\
\hline & Incomplete & 11 & $8.5 \%$ & 11 & $8.5 \%$ & & \\
\hline & Wrong & 117 & $90.0 \%$ & 2 & $1.5 \%$ & & \\
\hline
\end{tabular}

TABLE 4: Comparison of total pre-post knowledge test among student in the study sample $(n=130)$

Knowledge
Poor (<50)
Fair $(50-<75 \%)$
Good $(75 \%+)$
Range
Mean (SD)

\begin{tabular}{|c|c|c|c|}
\hline \multicolumn{3}{|c|}{ Assessment } \\
\hline \multicolumn{2}{|c|}{ Pre } & \multicolumn{2}{|c|}{ Post } \\
\hline No. & $\%$ & No. & $\%$ \\
\hline 126 & $96.9 \%$ & 1 & $0.8 \%$ \\
\hline 4 & $3.1 \%$ & 23 & $17.7 \%$ \\
\hline 0 & $0.0 \%$ & 106 & $81.5 \%$ \\
\hline & $1-14$ & $11-22$ \\
\hline $6.44(2.7)$ & $19.9(1.9)$ \\
\hline
\end{tabular}

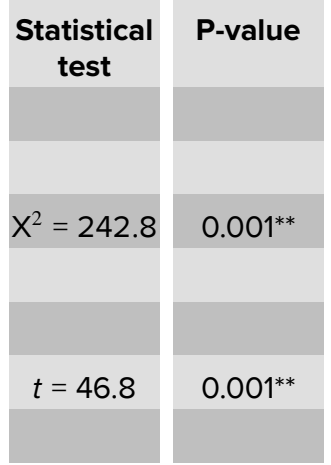

The results of pre-post total knowledge scores of female students in the study sample are presented in Table 4. It indicates statistically significant improvement in the total students' knowledge scores in the post-test compared to the pre-test, $P=0.001$. As seen in the table, the great majority of students $(96.9 \%)$ had poor knowledge pre-test, which was greatly improved post-test, where $81.5 \%$ had good knowledge.

\section{Discussion}

Working on preventing cervical cancer through screening is a valuable strategy to combat the increasing rate of the disease. Despite the provision of medical services 
and availability of screening tests, increasing people's risk awareness and supporting them to be actively engaged in disease prevention could be the best approach to increase screening rate. The current study showed that the majority of the participants despite having a prior knowledge of cervical cancer had not attended any educational programs. While social media was the main source of cervical cancer information, TV and newspapers were the second. These results are in line with a previous study conducted in Egypt that found $95.1 \%$ of the participant nurses did not attend any program about cervical cancer, but about two-third of them took their information from work experience followed by academic study and doctors [13]. In addition, similar results were found in India where $20 \%$ of the participants identified that reading newspapers is their source of cervical cancer information [10].

The finding of the present study supports previous studies where a significant improvement of post-test students' knowledge in all items of cervical cancer has been reported, which supports the implementation of educational programs especially in mass gathering locations such as universities and schools [13]. Educational programs were a crucial factor in applying cervical cancer awareness campaigns [14]. Furthermore, these programs enhance women's health beliefs, thereby helping in cervical cancer prevention and detection $[3,15]$.

According to the American Cancer Association guideline, Pap smear and the HPV DNA test are significant diagnostic tools [16]. Improvement in participants' awareness about HPV and its vaccine was evident taking into account the difference in the scores of the pre-and post-tests. Similar trend was found in previous studies conducted outside Saudi Arabia [17]. At pre-test, majority of the participants had poor knowledge about Pap smear, importance, procedures, timing, periodicity, and prior precautions. However, the post-test showed great improvement in the students' knowledge regarding all of these items. In the same line of findings, previous studies of similar intervention made significant positive enhancement in participants' knowledge noticing the difference between the pre- and post-tests [18].

In general, the study supports the findings of previous international studies proving overall cervical cancer knowledge improvements $[9,11,13]$. Therefore, it is imperative to recommend educational programs to attain cervical cancer awareness among target groups [1].

The study results recommend further similar initiatives within the university to raise the general awareness of all students. Furthermore, enhanced educational programs for cervical cancer awareness should be included in the nursing curriculum. From a community stand, community campaigns are warranted to raise public awareness on cervical cancer and Pap smear screening become a routine test for all women in childbearing age.

\section{Conclusion}

In this study, the majority of the participants had poor knowledge about cervical cancer pre-test. After delivering the educational intervention, the post-test indicated significant improvements in the participants' level of knowledge for almost all items. Therefore, 
the study results conclude that educational interventions about cervical cancer were successful in increasing awareness and knowledge among the study participants.

\section{Acknowledgments}

None.

\section{Ethical Considerations}

The college of nursing research ethics committee (REC-TUCN) approved the study proposal. Potential participants received an invitation including explanation of the study aim and procedures. Study data were treated confidentially and not utilized for academic purposes.

\section{Competing Interests}

None.

\section{Availability of Data and Material}

The data used in this study is available upon reasonable request.

\section{Funding}

None.

\section{References}

[1] WHO. (2020). WHO Technical Guidance and Specifications of Medical Devices for Screening and Treatment of Precancerous Lesions in the Prevention of Cervical Cancer 2020. Geneva, Switzerland: WHO.

[2] Marek, E., Dergez, T., Rebek-Nagy, G., et al. (2012). Effect of an educational intervention on Hungarian adolescents' awareness, beliefs and attitudes on the prevention of cervical cancer. Vaccine, vol. 30, no. 48 , pp. 6824-6832.

[3] Ahmed, S. R. H., Esa, A. S. M., and Mohamed El-zayat, O. S. (2018). Health Belief Model-based educational program about cervical cancer prevention on women knowledge and beliefs. Egyptian Nursing Journal, vol. 15, no. 1, pp. 39-49.

[4] Ombech, E. A., Muigai, A., and Wanzala, P. (2012). Awareness of cervical cancer risk factors and practice of Pap smear testing among female primary school teachers in Kasarani division, Nairobi Kenya. African Journal of Health Sciences, vol. 21, no. 21, pp. 121-132.

[5] Pimple, S. A. and Mishra, G. A. (2019). Global strategies for cervical cancer prevention and screening Minerva Ginecologica, vol. 71, no. 4, pp. 313-320.

[6] HPV Information Centre. (2019). Saudi Arabia Human Papillomavirus and Related Diseases Report. HPV Information Centre.

[7] Alsbeih, G. (2014). HPV infection in cervical and other cancers in Saudi Arabia: implication for prevention and vaccination. Frontiers in Oncology, vol. 4, p. 65.

[8] WHO. (2012). Health Education: Theoretical Concepts, Effective Strategies and Core Competencies-A Foundation Document T Guide Capacity Development of Health Educators. Geneva: WHO. 
[9] Mary, B. and D'Sa, J. L. (2014). Evaluation of an educational program on cervical cancer for rural women in Mangalore, Southern India. Asian Pacific Journal of Cancer Prevention, vol. 15, no. 16, pp. 66036608.

[10] Naik, P. R., Nagaraj, K., and Nirgude, A. S. (2012). Awareness of cervical cancer and effectiveness of educational intervention programme among nursing students in a rural area of Andhra Pradesh. Healthline, vol. 3, pp. 41-45.

[11] Naz, M. S. G., Kariman, N., Ebadi, A., et al. (2018). Educational interventions for cervical cancer screening behavior of women: a systematic review. Asian Pacific Journal of Cancer Prevention, vol. 19, no. 4, pp. 875-884.

[12] Siddiqui, A. F., Al Qahtani, S. Q., Al Qahtani, A. M., et al. (2018). Knowledge, attitudes and practice of burns prevention and first aid among medical students of King Khalid University, Saudi Arabia. Bangladesh Journal of Medical Science, vol. 17, no. 4, pp. 537-544.

[13] Abo-Lela, H., Mansour, S. E., Rafik Ibrahem Barakat, R. I., et al. (2017). Effect of applying educational sessions on the nurses' knowledge regarding cervical cancer. IOSR Journal of Nursing and Health Science, vol. 6, pp. 29-36.

[14] Pirzadeh, A. and Mazaheri, M. A. (2012). The effect of education on women's practice based on the health belief model about pap smear test. International Journal of Preventive Medicine, vol. 3, no. 8 , pp. 585-590.

[15] Atwa, A. M. E., Hassan, H. E., and Ahmed, S. I. (2019). The impact of a hospital-based awareness program on the knowledge of patients about breast cancer and cancer cervix. International Journal of Nursing Studies, vol. 4, no. 1, p. 20.

[16] Tsikouras, P., Zervoudis, S., Manav, B., et al. (2016). Cervical cancer: screening, diagnosis and staging Journal of the Balkan Union of Oncology, vol. 21, no. 2, pp. 320-325.

[17] Kessler, T. A. (2017). Cervical cancer: prevention and early detection. Seminars in Oncology Nursing, vol. 33, no. 2, pp. 172-83.

[18] Devi, A. M. (2019). To assess the effectiveness of Planned Teaching Program (PTP) on knowledge regarding early detection and prevention of cervical cancer among women: pre-experimental study. International Journal of Nursing Education, vol. 11, no. 2, pp. 1-6. 